Article

\title{
Biogenic Synthesis of Silver Nanoparticles Using Phagnalon niveum and Its In Vivo Anti-Diabetic Effect against Alloxan-Induced Diabetic Wistar Rats
}

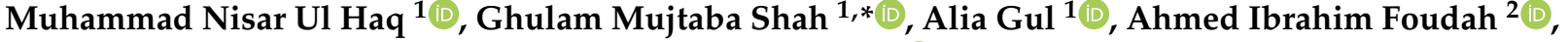 \\ Mohammad Hamed Alqarni ${ }^{2}$, Hasan Soliman Yusufoglu ${ }^{3} \mathbb{D}$, Masroor Hussain ${ }^{4}$, Huda Mohammed Alkreathy ${ }^{5}$, \\ Ihsan Ullah ${ }^{6}$, Amir Muhammad Khan ${ }^{7}$, Shahid Jamil ${ }^{4}$, Mushtaq Ahmed ${ }^{4}$ and Rahmat Ali Khan ${ }^{4, *}$
}

check for updates

Citation: Ul Haq, M.N.; Shah, G.M.; Gul, A.; Foudah, A.I.; Alqarni, M.H.; Yusufoglu, H.S.; Hussain, M.; Alkreathy, H.M.; Ullah, I.; Khan, A.M.; et al. Biogenic Synthesis of Silver Nanoparticles Using Phagnalon niveum and Its In Vivo Anti-Diabetic Effect against Alloxan-Induced Diabetic Wistar Rats. Nanomaterials 2022, 12, 830. https://doi.org/ $10.3390 /$ nano12050830

Academic Editors: Sergio Gómez-Graña, Alejandro Baeza and Gonzalo Villaverde

Received: 11 January 2022

Accepted: 24 February 2022

Published: 1 March 2022

Publisher's Note: MDPI stays neutral with regard to jurisdictional claims in published maps and institutional affiliations.

Copyright: (C) 2022 by the authors. Licensee MDPI, Basel, Switzerland. This article is an open access article distributed under the terms and conditions of the Creative Commons Attribution (CC BY) license (https:// creativecommons.org/licenses/by/ $4.0 /)$.
1 Department of Botany, Hazara University Mansehra, Mansehra 21300, Pakistan; mnhq1987@gmail.com (M.N.U.H.); aliagulbotanist@gmail.com (A.G.)

2 Department of Pharmacognosy, College of Pharmacy, Prince Sattam Bin Abdulaziz University, Al-Kharj 11942, Saudi Arabia; a.foudah@psau.edu.sa (A.I.F.); m.alqarni@psau.edu.sa (M.H.A.)

3 Department of Pharmacognosy \& Pharmaceutical Chemistry, College of Dentistry \& Pharmacy, Buraydah Private Colleges, Buraydah 51418, Saudi Arabia; hasan.yusuf@bpc.edu.sa

4 Department of Biotechnology, University of Science and Technology Bannu, Bannu 28100, Pakistan; masroorktk@gmail.com (M.H.); shahidberg@uop.edu.pk (S.J.); mushtaq121@yahoo.com (M.A.)

5 Department of Pharmacology, Faculty of Medicine, King Abdulaziz University, Jeddah 21589, Saudi Arabia; halkreathy@gmail.com

6 Department of Botany, University of Science and Technology Bannu, Bannu 28100, Pakistan; iukwazir@gmail.com

7 Department of Botany, University of Mianwali, Mianwali 42200, Pakistan; khanamir62@yahoo.com

* Correspondence: gmujtabashah72@yahoo.com (G.M.S.); rahmatgul_81@yahoo.com (R.A.K.)

Abstract: Background: Type-2 diabetes mellitus (T2DM) is a non-communicable, life-threatening syndrome that is present all over the world. The use of eco-friendly, cost-effective and green synthesised nanoparticles (NPs) as a medicinal therapy in the treatment of T2DM is an attractive option. Aim: The present study aimed to evaluate the anti-diabetic potential of the phyto-synthesised silver nanoparticles (AgNPs) obtained from Phagnalon niveum plant methanolic extract. Methods: The green synthesised AgNPs made from Phagnalon niveum plant methanolic extract were analysed by Ultraviolet-Visible (UV-Vis) spectroscopy, and the functional groups involved in the reduction of the silver ions $\left(\mathrm{Ag}^{+}\right)$were characterised by Fourier Transform Infrared (FTIR) spectroscopy. The size and crystallinity were assessed via X-ray Diffraction (XRD). The morphology of AgNPs was confirmed using Scanning Electron Microscopy (SEM). The amount of silver (Ag) was estimated via energy dispersive X-ray (EDX) analysis. An intraperitoneal injection of $200 \mathrm{mg}$ alloxan per $\mathrm{kg}$ albino Wistar rats' body weight, at eight weeks old and weighing 140-150 g, was used to induce diabetes mellitus ( $N=25 ; n=5$ /group). Group C: untreated normal control rats that only received distilled water, group DAC: diabetic control rats that received alloxan $200 \mathrm{mg} / \mathrm{Kg}$ body weight, DG: diabetic rats treated with glibenclamide at $0.5 \mathrm{mg} / \mathrm{kg}$ body weight, DE: diabetic rats that received methanolic $P$. niveum extract at $10 \mathrm{mg} / \mathrm{Kg}$ body weight, and DAgNPs: diabetic rates that received AgNPs synthesised from $P$. niveum at $10 \mathrm{mg} / \mathrm{kg}$ body weight. The blood glucose levels were monitored on days 0,7 , and 14 , while lipid, liver, and kidney profiles were checked after dissection at the end of treatment (day 21). On the final day of the period study (day 21), an oral glucose tolerance test was carried out by administering orally $2 \mathrm{~g} / \mathrm{kg}$ body weight of glucose to the respective groups, and the blood glucose level was checked. A fasting glucose level was measured using a glucometer. Urine samples were collected from each animal and analysed using lab-made assay kits for glucose, bilirubin, $\mathrm{pH}$, leukocytes, and nitrite, among other factors. For statistical analyses, a one-way ANOVA and Dunnett's test were applied. Results: The green-mediated synthesis of AgNPs using P. niveum methanolic extract produced spherical and mono-dispersed NPs with a size ranging from 12 to $28 \mathrm{~nm}$ (average: $21 \mathrm{~nm}$ ). Importantly, a significant reduction of blood glucose levels and an increase in body weight, as well as a remarkable improvement in lipid, liver, and kidney profiles, were noticed. Conclusions: The biosynthesised AgNPs significantly improved the abnormalities in body weight, urine, and serum levels, indicating that it is a promising anti-diabetic agent. 
Keywords: Phagnalon niveum; silver nanoparticles; diabetes mellitus; alloxan animal model; green nanomedicine

\section{Introduction}

Nanotechnology has recently taken on a significant role in scientific research and development. The field of nanotechnology deals with the manufacture and development of nanoscale particles with a size range of 1-100 nanometres $(\mathrm{nm})$, comparatively small compared to bulk materials [1]. There is a current focus on the creation of non-materials and particles for delivery purposes, with consideration given to the location of action, drug size, and duration of the drug delivery order [2].

Due to its usage in a variety of sectors, nanotechnology is recognised as interdisciplinary due to the fact that it may be used as a biological diagnostic tool as well as in manufacturing tools and biosensors [3,4]. Developing nanotechnology throughout that time period has dubbed the twenty-first century the "Nano Century" [5]. Chemical, physical, and green methods are all used to synthesise nanoparticles. The utilisation of biological plants, bacteria, and other organisms in nanoparticle production is becoming more prevalent these days [4]. High pressures and high temperatures are used in the physical technique to synthesise nanoparticles. The reducing and stabilizing agents used in the chemical technique are very hazardous and expensive. The green technique of nanoparticle synthesis uses plants and plant parts, such as stems, bark, leaves, roots, seeds, flowers, fruits, gum, and buds, that are nontoxic, environmentally friendly, and cheap [6].

Diabetes mellitus is a serious hazard to human health across the globe, given its associated consequences [5]. In the whole world, it is among the top five leading causes of death [7]. Diabetes mellitus is a collection of metabolic illnesses that develop as a result of hyperglycaemia and glucose intolerance (DM). There are two commonly recognised kinds of diabetes mellitus. Type- 1 diabetes is characterised by insufficient insulin release from the pancreatic cells, whereas type-2 diabetes is characterised by the development of the body's insulin resistance [8]. More than $90 \%$ of diabetics across the world have type-2 diabetes mellitus [9]. This population is growing at an alarming pace. Diabetes mellitus affects more than 280 million people in the United States, and the high incidence of the disease might lead to an additional 400 million people being diabetic by 2030 [10].

There is a significant frequency of diabetes mellitus in contemporary lifestyles due to a lack of physical exercise, obesity, ethnicity, advanced age, and genetic polymorphism [11,12]. Type-2 diabetics have insulin resistance in their bodies, which prevents their cells from taking glucose from the blood, resulting in hyperglycaemia or high blood glucose levels. Without treatment, persistent hyperglycaemia may cause metabolic disorders in a variety of organs, including the kidneys. These metabolic problems may be deadly. Even if one does not die, diabetes can still lead to secondary issues, such as kidney, heart, liver, and eye illness, as well as erectile dysfunction and blindness [13,14].

The main cause of diabetes is reactive oxygen species (ROS)-induced oxidative stress, which leads to the malfunctioning of cells, insulin resistance, and poor glucose tolerance. ROS are formed when glucose and fatty acids are overloaded due to overeating and inactivity [15]. Apoptotic cell death is a consequence of physiological and pathological stress on the pancreatic cells [16]. Researchers also found a link between oxidative stress and pancreatic cell death, as well as diabetes-related side effects. They claim that hyperglycaemia-induced diabetic problems are primarily caused by an imbalance between ROS and TORCH, which raises oxidative stress and causes apoptosis [17]. As a result, by decreasing ROS production, these diabetes problems may be successfully managed.

Changes in food and lifestyle, as well as the oral delivery of anti-diabetic medications, are critical in reducing ROS formation during diabetes therapy. Whether you have type- 1 or type-2 diabetes, it is essential to keep blood glucose levels within the normal range (70-140 mg/dL). Finding a medicine that works well for treating diabetes is a typical 
challenge. In the treatment of diabetes, many anti-diabetic and hypoglycaemic medications, such as sulfonylureas and biguanides, have been launched. However, these treatments do not give long-term control over the blood glucose level. These medications are also less prevalent since their extended usage leads to toxicity and unintended side effects, such as gastrointestinal pain, hypoglycaemia, pancreatic degeneration, and liver damage in the body [18]. Finding novel hypoglycaemic medications and hypoglycaemic agents with fewer side effects and better effectiveness is a worthwhile endeavour, and this has been the focus of previous research.

Phagnalon niveum is an Asteraceae family member with an upright or decumbent stem, 30-40 cm in height, with a few to an abundant number of developed branches, and a thick, snow-white cottony fleece covering the stem and the branches. There are many foliated branches on this plant. A wide range of leaf shapes and sizes are seen in this species, with the most common being lanceolate $(8-35 \mathrm{~mm}$ ) with an undulate or shallowly lobed margin, and the least common being oblanceolate (dentate or shallowly lobed), all having a sessile base. Since ancient times, the peduncles have been upright, measuring $20-70 \mathrm{~mm}$ and covered in a white cottony fleece that bears a single capitulum. It has multiflorous capitula that are 8-12 mm wide. Its external phyllaries are subulate to barely lanceolate and measure 2-2.5 mm in length. Its centre phyllaries are 3-3.5 mm wide and measure $0.5 \mathrm{~mm}$ in length. The latter are subulate to barely lanceolate and gradually narrow into an acicular point with whole edges. Their pinnacles are subulate to barely lanceolate. The flowers have no preference for tubulose, and are about 5-6 $\mathrm{mm}$ long, tube glabrous, with projections slightly adjusted; they are bristly at the ends, and have tube florets with no preference. Sub-exserted anthers contain completely ecaudate bases, including subincluded, papillose style, bifid and adjusted disgrace markings. Insufficiently bristly Pappus setae, about one millimetre long, barbellate almost all the way to the base [19]. Phagnalon niveum (Figure 1) is traditionally used in the treatment of diabetes mellitus and has not been investigated pharmacologically. Therefore, a comparative analysis of the anti-diabetic activity of the plant extract and green synthesised NPs was arranged.

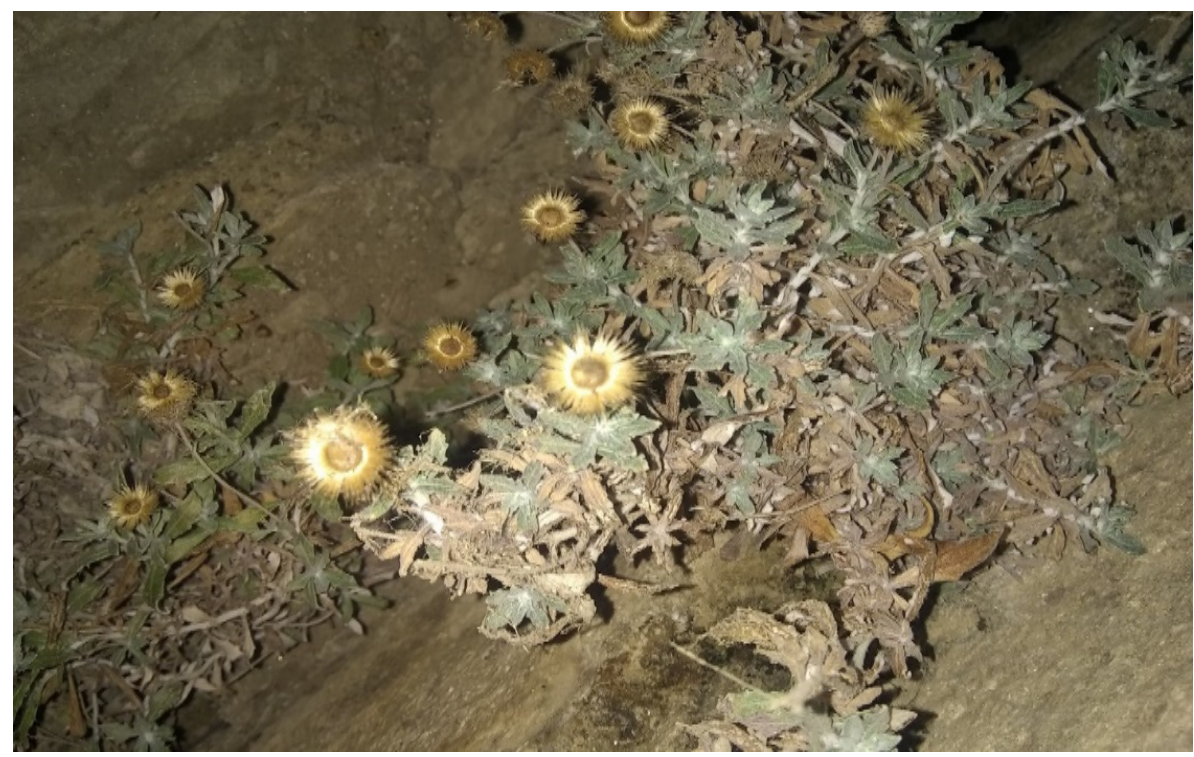

Figure 1. Phagnalon niveum Plant.

\section{Material and Methods}

\subsection{Chemicals and Instruments}

We used methanol, ddH $\mathrm{d}_{2} \mathrm{O}, \mathrm{AgNO}_{3}, \mathrm{NaOH}$, Aqua regia, DMSO, formalin, normal saline solution, gastric cannula, disposable syringes, a dissecting board, a dissecting box, diethyl ether, and cotton.

UV-Vis spectroscopy (Specord 200 plus Jena, Germany) 
FTIR spectroscopy (Thermo Fisher Scientific, Waltham, MA, USA, Nicolet iS50 FT-IR)

XRD (JDX 3532, JEOL, Tokyo, Japan)

SEM (JSM 5910 JEOL, Japan)

EDX (INCA 200, Oxford, UK)

\subsection{Plant Collection}

During the months of April and May 2019, Phagnalon niveum Edgew (Figure 1) was collected in the Talash District, Dir Lower Khyber Pakhtunkhwa, Pakistan. The plant was properly identified by taxonomist Prof. Dr. Ghulam Mujtaba Shah and a voucher specimen (PN-134) has been submitted to the herbarium of the Department of Botany at Hazara University, Mansehra, for future reference. After identification, the plant was properly washed with water to remove dust particles and was shed-dried for 15 days at room temperature according to the previous investigations [20].

\subsection{Extract Preparations of Phagnalon niveum Edgew}

After fifteen days, the plant was ground to a fine powder and $100 \mathrm{~g}$ of powder was soaked in $300 \mathrm{~mL}$ of methanol and shaken vigorously. After 7 days, the filtrated Whatman No. 1 filter paper was dried with a rotary evaporator to obtain a thick, viscous, gummy crud extract. The crude extract was weighed and stored at $4{ }^{\circ} \mathrm{C}$ for further activities.

\subsection{Phytochemical Screening}

According to previously published protocols, numerous phytochemical screening tests were conducted [21,22]. The following tests were used in order to identify the phytochemicals.

\subsection{Test}

\subsubsection{Test for Alkaloids}

Using Molisch's Carbohydrate Test, two drops of an alcoholic naphthol solution are added to $2 \mathrm{mM}$ of filtrate, and the mixture is agitated vigorously before $1 \mathrm{mM}$ of concentrated sulphuric acid is slowly poured along the tube's sides and left to stand for one min. Carbohydrates are indicated by a violet ring [21,22].

\subsubsection{Test for Glycosides}

For the determination of glycosides, the Bontrager test was used. This involves hydrolysing $50 \mathrm{mg}$ of extract in a water bath for $2 \mathrm{~h}$ with strong hydrochloric acid before filtering. A chloroform layer is separated, and a $10 \%$ ammonia solution is added to $2 \mathrm{~mL}$ of filtered hydrolysate. The chloroform layer is then added to the $10 \%$ ammonia solution and shaken. Glycosides are indicated by a pink tint [21,22].

\subsubsection{Test for Saponins}

The saponins in $50 \mathrm{mg}$ of extract are detected by diluting it with distilled water and making it into a $20 \mathrm{~mL}$ solution. For $15 \mathrm{~min}$, the suspension is shaken vigorously in a graduated cylinder. Saponins are detected by looking for a $2 \mathrm{~cm}$ layer of foam [21,22].

\subsubsection{Testing for Proteins and Amino Acids}

Here, $100 \mathrm{mg}$ of extract is dissolved in $10 \mathrm{~mL}$ of distilled water and filtered through Whatman No. 1 filter paper [21,22].

\section{Protein Biuret Test}

A drop of $2 \%$ copper sulphate solution is added to a $2 \mathrm{~mL}$ aliquot of the filtrate. To this, $1 \mathrm{~mL}$ of $95 \%$ ethanol is added, and then an excess of potassium hydroxide pellets is poured over the top. The presence of proteins is indicated by the ethanolic layer's pink colour [21,22]. 
Test for Amino Acids

The amino acid test using ninhydrin was performed. To $2 \mathrm{~mL}$ of aqueous filtrate, add two drops of ninhydrin solution (10 $\mathrm{mg}$ ninhydrin in $200 \mathrm{~mL}$ of acetone). The presence of amino acids is indicated by a distinctive purple hue $[21,22]$.

\subsubsection{Test for Phytosterols}

A biochemical assay for phytosterols involves dissolving a $50 \mathrm{mg}$ extract in 2 millilitres of acetic anhydride. Add a few drops of concentrated sulfuric acid around the tube's rim and stir carefully until the acid dissolves completely. Phytosterols are visible as a wide range of colour changes [21,22].

\subsubsection{Test for Phenols}

Phenolic compounds are detected using the ferric chloride test, which involves dissolving $50 \mathrm{mg}$ of the extract in $5 \mathrm{~mL}$ of distilled water. A few drops of a neutral ferric chloride solution (which contains $5 \%$ ferric chloride) are added to this. Phenolic substances are indicated by a dark-green hue [21,22].

\subsubsection{Test for Flavonoids}

Using an alkaline reagent solution, an extract is treated with a $10 \%$ solution of ammonium hydroxide to look for flavonoids. Flavonoids are shown by a yellow glow [21,22].

\subsubsection{Test for Terpenoids}

An extract of the plant is combined with $2 \mathrm{~mL}$ of chloroform $\left(\mathrm{CHCl}_{3}\right)$ and $3 \mathrm{~mL}$ of concentrated $\mathrm{H}_{2} \mathrm{SO}_{4}$ to create a layer, and this mixture is put on the sample. The presence of terpenoids in the interface is indicated by a reddish-brown colouring [21,22].

\subsubsection{Test for Tannins}

To find out whether there are any tannins present, use the following test: To $1 \mathrm{mM}$ of plant extract, two millilitres of $5 \%$ ferric chloride is added. The presence of tannins is indicated by the formation of a dark-blue or greenish-black coloration [21,22].

\subsubsection{Test for Quinones}

The extract was tested for quinones by adding $1 \mathrm{~mL}$ of concentrated sulphuric acid to $1 \mathrm{~mL}$ of extract. The presence of quinones is indicated by the formation of a red hue $[21,22]$.

\subsubsection{Test for Coumarins}

To test for coumarins, check for the presence of coumarins by performing the following test: $1 \mathrm{~mL}$ of the extract is mixed with $1 \mathrm{~mL}$ of $10 \%$ sodium hydroxide solution. The presence of coumarins is indicated by the formation of a yellow colour [21,22].

\subsection{Synthesis of Silver Nanoparticles}

The synthesis of silver nanoparticles was carried out using the method of Khan et al. (2018). After dissolving $100 \mathrm{mg}$ of methanol crude in $50 \mathrm{~mL}$ of ddH2O, various amounts of extract (100 L, $300 \mathrm{~L}, 500 \mathrm{~L}, 800 \mathrm{~L}, 1 \mathrm{~mL}, 1.5 \mathrm{~mL}, 2 \mathrm{~mL}, 2.5 \mathrm{~mL}$, and $3 \mathrm{~mL}$ ) were placed in a 1 mmol solution of $\mathrm{AgNO}_{3}$ with various $\mathrm{pH}$ ranges $(6,7,8,9,10,11$, and 12). At $\mathrm{pH} 11$, the required nanoparticles are synthesised.

\subsection{Characterisation of Silver Nanoparticles}

Various characterisation techniques were used, such as UV-Vis, FTIR, XRD, SEM and EDS.

The surface plasma resonance (SPR) bonds of the plant-mediated silver nanoparticles were characterised using UV-Vis spectroscopy (Specord 200 plus Germany) in the range of 200-800 nm wavelength [23]. The surface and surface composition were analysed through 
FTIR spectroscopy (Nicolet iS50 FT-IR Thermo Fisher Scientific USA) in the mid-range of IR $4000-500 \mathrm{~cm}^{-1}$.

An X-ray diffraction technique was used to investigate the size and crystal structure of silver nanoparticles [23]. To check the morphology of silver nanoparticles, the SEM of the nanoparticles was performed by using a Scanning Electron Microscope (JSM 5910). To analyse the elemental composition of the analysed volume, EDX was performed on phyto-synthesised silver nanoparticles [24].

\subsection{Induction of Diabetes}

For this study, the Sengottaiyan et al. [24] protocol was used. All the experimental protocols for in vivo animal assays have been approved by the ethical committee. An intraperitoneal injection of $200 \mathrm{mg}$ alloxan per $\mathrm{kg}$ of albino Wistar rats' body weight, at eight weeks old and weighing 140-150 g, was used to induce diabetes mellitus (DM). If the blood glucose level rose to $220 \mathrm{mg} / \mathrm{dL}$ after $72 \mathrm{~h}$, the animals were considered to be diabetic.

\subsection{Acute Toxicity}

AgNPs were tested for acute toxicity by administering doses of 10 and $20 \mathrm{mg}$ per $\mathrm{kg}$ of body weight. During the $2 \mathrm{~h}$ period, any changes in neurology, physiology, or behaviour and fatality or lethality were recorded for up to $72 \mathrm{~h}$ with daily monitoring. The experiment was conducted by using $10 \mathrm{mg} / \mathrm{kg}$ AgNPs in accordance with a previously documented procedure [25].

\subsection{Experimental Treatments in Animals and Ethics}

The albino Wistar rates were purchased from the National Institute of Health (NIH) Sciences, Islamabad, Pakistan. They were fed with the NIH-recommended pellets of feed.

In a further step, the animals $(n=25)$ were divided into five groups, with five animals in each group, namely:

C: untreated normal rats (normal control, who received only distilled water);

DAC: diabetic control, with rats receiving alloxan $200 \mathrm{mg} / \mathrm{kg}$ body weight;

DG: diabetic rats treated with glibenclamide at $0.5 \mathrm{mg} / \mathrm{kg}$ body weight;

DE: diabetic rates treated with methanolic $P$. niveum extract at a dose of $10 \mathrm{mg} / \mathrm{kg}$ body weight;

DAgNPs: diabetic rats that received AgNPs synthesised from P. niveum at $10 \mathrm{mg} / \mathrm{kg}$ body weight.

After 21 days, the animals were sacrificed.

\subsection{Oral Glucose Tolerance Test}

The oral glucose tolerance test was performed on the final day of the period study (day 21), and the blood glucose level was checked periodically by collecting blood from the tail tip of each animal at $0,30,60,90$, and $120 \mathrm{~min}$ after orally administering $2 \mathrm{~g} / \mathrm{kg}$ body weight of glucose to the respective groups. The fasting glucose level was also assessed using a glucometer (Accu-check Instant, Roche, Germany).

\subsection{Serological Analysis}

A retro-orbital puncture was used to obtain blood samples, which were then centrifuged at $1000 \mathrm{rpm}$ for $15 \mathrm{~min}$. The serum was then collected and kept cold $\left(-80^{\circ} \mathrm{C}\right)$ until needed. Alanine aminotransferase (ALT), alkaline phosphatase (ALP), bilirubin, total protein, bilirubin, creatinine, and high-density lipoprotein-cholesterol (HDL-c) were measured using the technique previously described [26-29]. 


\subsection{Urine Analysis}

For each animal, urine samples were collected and various levels were assessed, namely, leukocytes, nitrite, urobilinogen, protein, $\mathrm{pH}$, blood, specific gravity, ketone, bilirubin, and glucose.

\subsection{Statistical Analysis}

All data from three independent experiments were expressed as mean SD, and the statistical significance between groups was determined using a one-way ANOVA followed by Dunnett's test in Origin 18. At a $p$-value of 0.05 , the data would be considered significant.

\section{Results}

\subsection{Phytochemical Analysis}

Biochemical screening results showed that phenols, proteins, tannins, flavonoids, alkaloids, quinones, sterols, carbohydrates, amino acids, terpenoids, and coumarins were present in the crude extract of $P$. niveum. However, the crude extract did not show any colour change for saponins and glycosides tests (Table 1).

Table 1. Qualitative phytochemical analysis of methanol extract of Phagnalon niveum.

\begin{tabular}{ccc}
\hline Tests & Present (+) & Absent (-) \\
Phenols & + & - \\
Proteins & + & - \\
Glycosides & + & \\
Tannins & + & \\
Flavonoids & \\
Alkaloids & + \\
Saponins & + \\
Quinones & + \\
Sterols & + \\
Test for Carbohydrates & + \\
Terpenoides & + \\
Coumarins & + \\
\hline
\end{tabular}

\subsection{Synthesis and Characterisation of Silver Nanoparticles}

\subsubsection{Green Synthesis of AgNPs}

Various amounts $(0.1,0.3,0.5,0.8,1,1.5,2,2.5$, and $3 \mathrm{~mL})$ of $P$. niveum extracts were mixed with a silver nitrate $\left(\mathrm{AgNO}_{3}\right)$ solution $(0.085 \mathrm{~g}$ by weight and $1 \mathrm{mM}$ solution $)$ and the colour changed from yellowish to dark brown, which indicated the reduction of silver ions $\left(\mathrm{Ag}^{+}\right)$and the synthesis of NPs (Figure 2a).

\subsubsection{UV-Vis Spectroscopy}

The synthesis of AgNPs was confirmed by using the UV-Vis spectroscopy technique. The mechanism of synthesis of AgNPs was explained by the surface plasmon resonance (SPR) effect (Figure 2b). The P. niveum plant extract displays a high number of phenols, proteins, tannins, flavonoids, alkaloids, quinones, sterols, carbohydrates, amino acids, terpenoids, and coumarins, which contribute to the formation of AgNPs. Similarly, the UV-Vis absorbance spectrum of AgNPs at various concentrations and at different time intervals revealed a maximum absorbance peak between 360 and $410 \mathrm{~nm}$, with an intensity varying between 0.5 and 0.9 (Figure $2 \mathrm{~b}$ ). The difference in the wavelength was most likely due to the different sizes of AgNPs. 


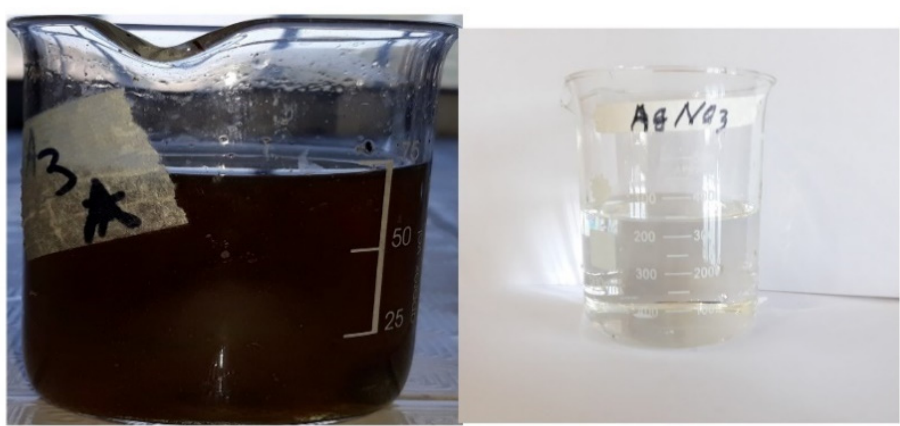

Plant Extract
$+$

AgNO3 Solution

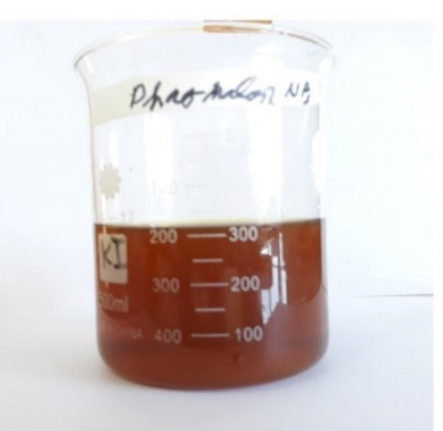

Silver Nanoparticles

(a)

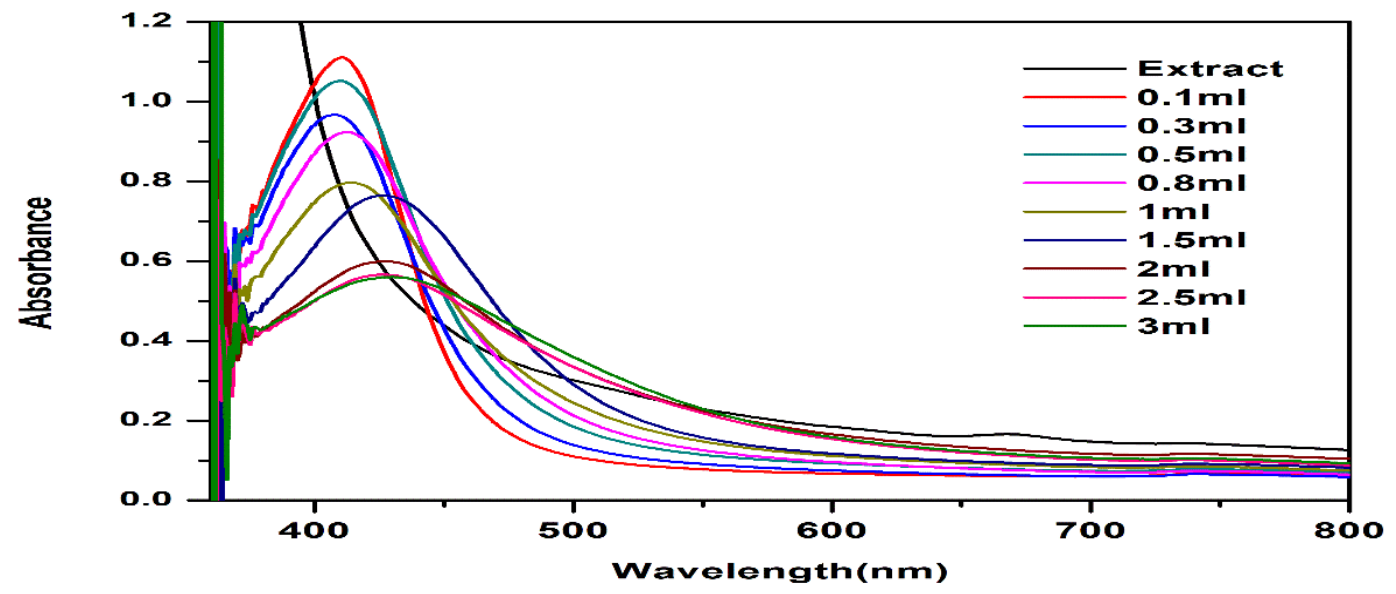

(b)

Figure 2. (a): Synthesis of AgNPs and colour change; (b): UV-Vis spectroscopic study of $P$ niveum AgNPs.

\subsubsection{Fourier-Transform Infrared Spectroscopy}

Figure 3a shows a major FTIR peak of the plant crude extract, observed at $3284.59 \mathrm{~cm}^{-1}$, which is assigned to the $\mathrm{O}-\mathrm{H}$ stretching and bending bond. The $\mathrm{O}-\mathrm{H}$ band gave rise to a broad peak, and this band verifies the presence of phenols. The peak at $2925 \mathrm{~cm}^{-1}$ is attributed to - $\mathrm{CH} 2-($ methylene) stretching, which gave rise to two $\mathrm{C}-\mathrm{H}$ stretching bands, corresponding to symmetric and asymmetric modes of stretching. The peak at $2362.3 \mathrm{~cm}^{-1}$ shows $\mathrm{O}-\mathrm{H}$ stretching. In Figure 3, the peaks at $1597 \mathrm{~cm}^{-1}$ show a $\mathrm{C}=\mathrm{O}$ for the ring and the peaks at $1633 \mathrm{~cm}^{-1}$ show the conjugation of $\mathrm{C}=\mathrm{O}$ with phenyl compounds. The peak at $1377.27 \mathrm{~cm}^{-1}$ refers to $\mathrm{C}-\mathrm{O}-\mathrm{H}$ bending, and vibrations are assigned to $\mathrm{CH}_{3}$. The peak at $1262.47 \mathrm{~cm}^{-1}$ shows strong $\mathrm{C}-\mathrm{O}$ single bond stretching and vibrations that indicate the presence of phenols. The peak at $1023 \mathrm{~cm}^{-1}$ shows out of plan $\mathrm{C}-\mathrm{H}$ bending and the vibration of the bend, which indicates the presence of an aromatic ring. The presence of this absorption in the IR region shows that the plant extract contains cyclic aromatic phenols, such as those found in flavonoids. Interestingly, the peaks observed in the IR spectrum of the synthesised AgNPs are shifted and decreased in intensity, which strongly suggests that plant biomolecules interact with AgNPs, most probably through their oxygen functionalities, which act as reducing and capping agents (Figure $3 \mathrm{~b}$ ). 


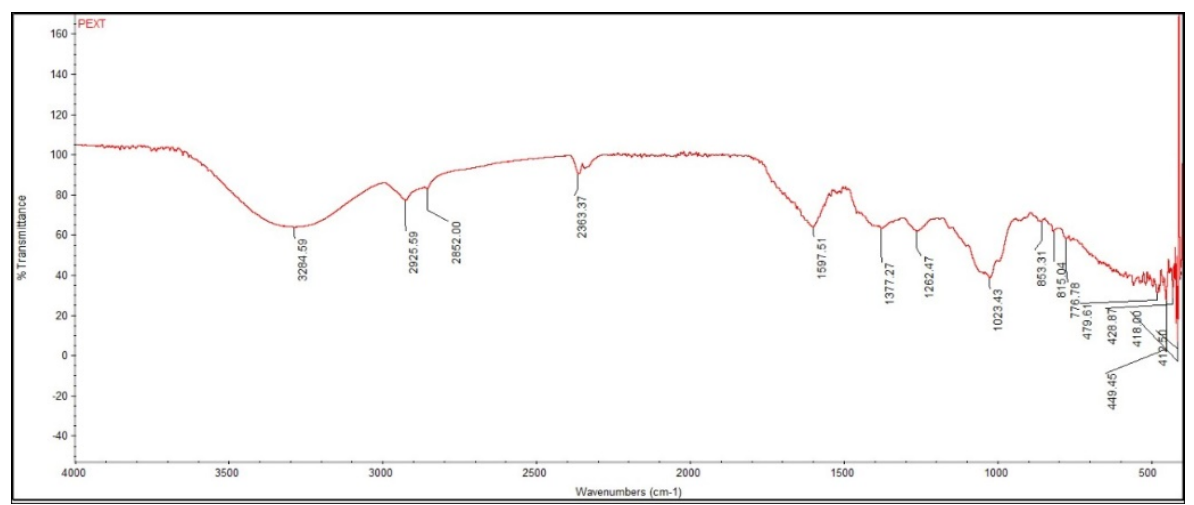

(a)

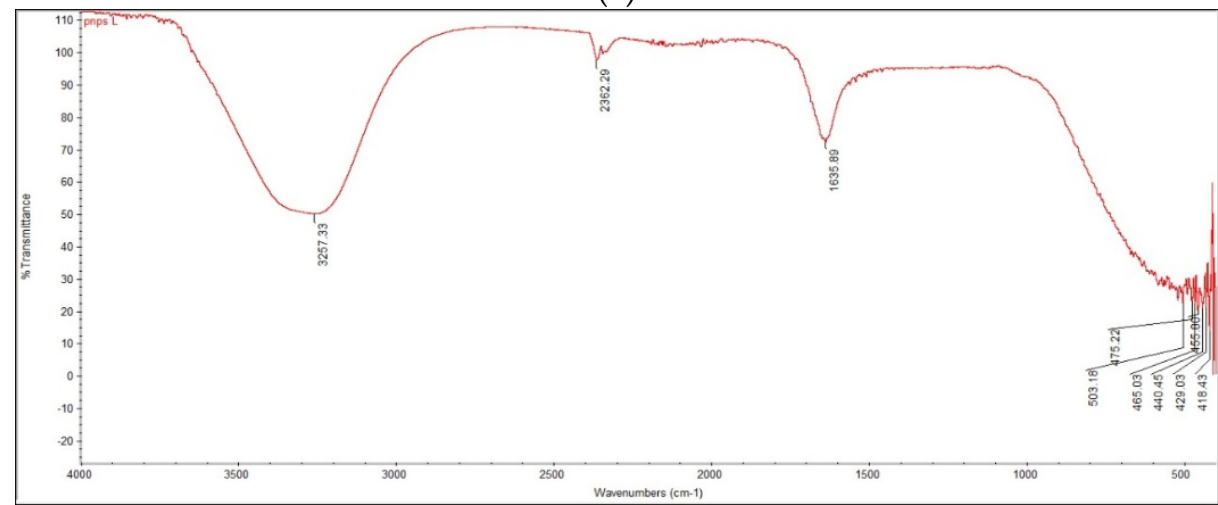

(b)

Figure 3. (a) FTIR spectra of P. niveum methanol extract. (b) FTIR spectra of AgNPs.

\subsubsection{XRD Analysis}

Then, we sought to confirm the crystalline nature of the biosynthesised PAgNPs with an XRD spectroscopic study. As shown in Figure 4, the XRD pattern shows a number of Bragg reflections at two values of $27.76^{\circ}, 32.14^{\circ}, 38.09^{\circ}, 46.25^{\circ}, 54.84^{\circ}, 57.3^{\circ}, 64.44^{\circ}$, and $77.4^{\circ}$, which correspond to the (111), (200), (200), (220), (311), (222), (220), and (311) sets of planes, respectively. These findings support the presence of face-centred cubic AgNPs. The lattice constant calculated for this structure was a 14 of $4.0855 \mathrm{~A}$. The unassigned peaks might have resulted from the plant extract-dependent capping agent involved in the stabilisation of AgNPs, and the average size of the AgNPs was $21 \mathrm{~nm}$.

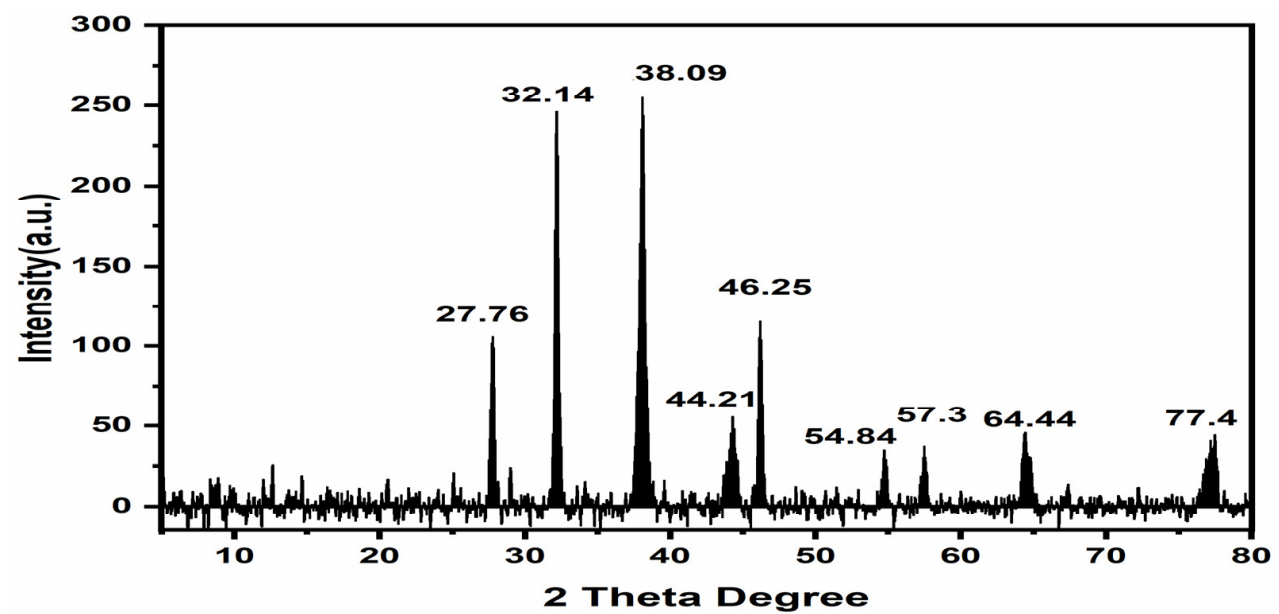

Figure 4. XRD pattern of $P$ niveum AgNPs. 


\subsubsection{SEM Analysis}

To determine the shape of the green AgNPs, SEM analysis was performed using centrifuged powder of AgNPs. As shown in (Figure 5), they were spherical in shape, and did not agglomerate (even after 7 days).

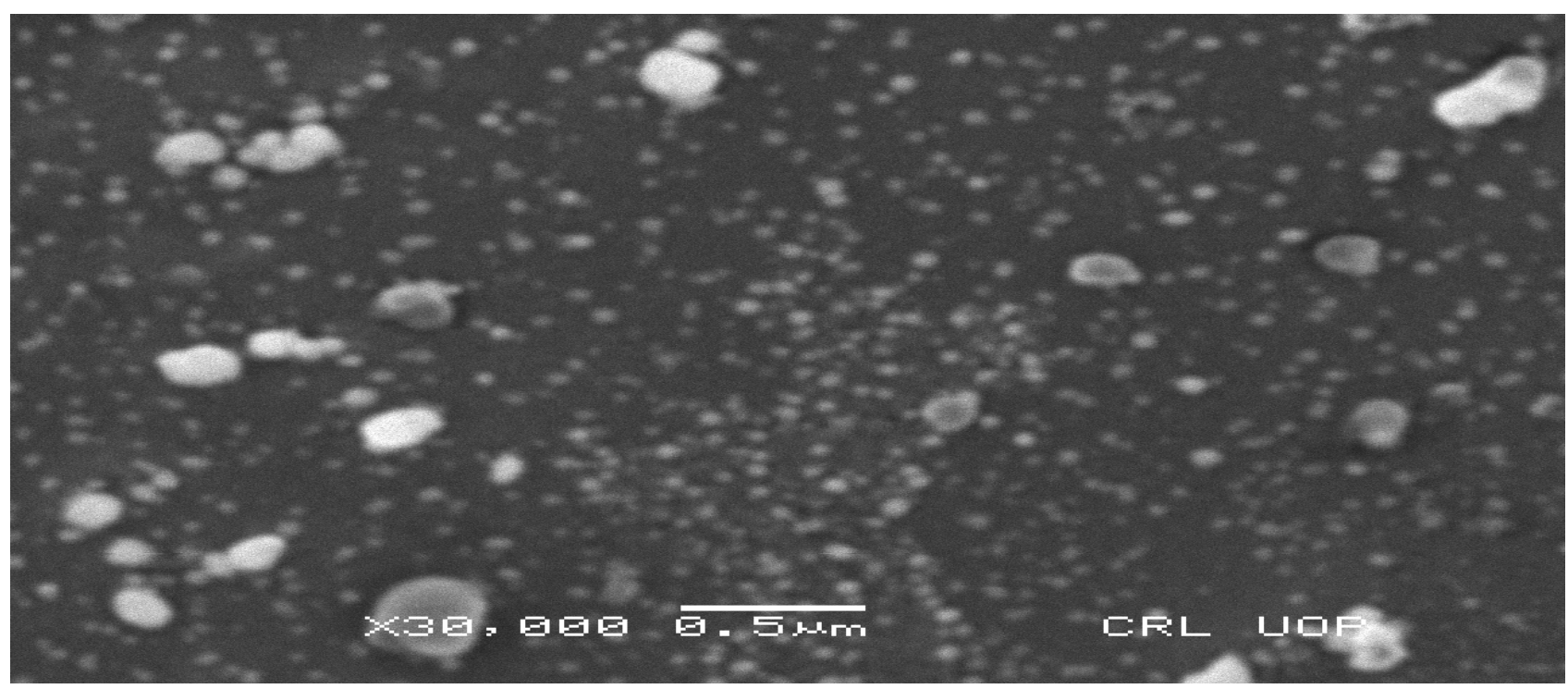

Figure 5. SEM analysis of P. niveum AgNPs.

\subsubsection{EDX Analysis}

The elemental configuration of the biosynthesised AgNPs was established using EDX, a detector connected to the SEM machine (Figure 6). The plotted graph exhibited a strong peak at $3 \mathrm{Kev}$, revealing the presence of Ag and confirming the existence of AgNPs. The Ag element accounted for $65.69 \%$ of the total composition. EDX analysis also revealed the presence of other elements, such as $\mathrm{C}, \mathrm{N}, \mathrm{O}$, and $\mathrm{Cl}$.

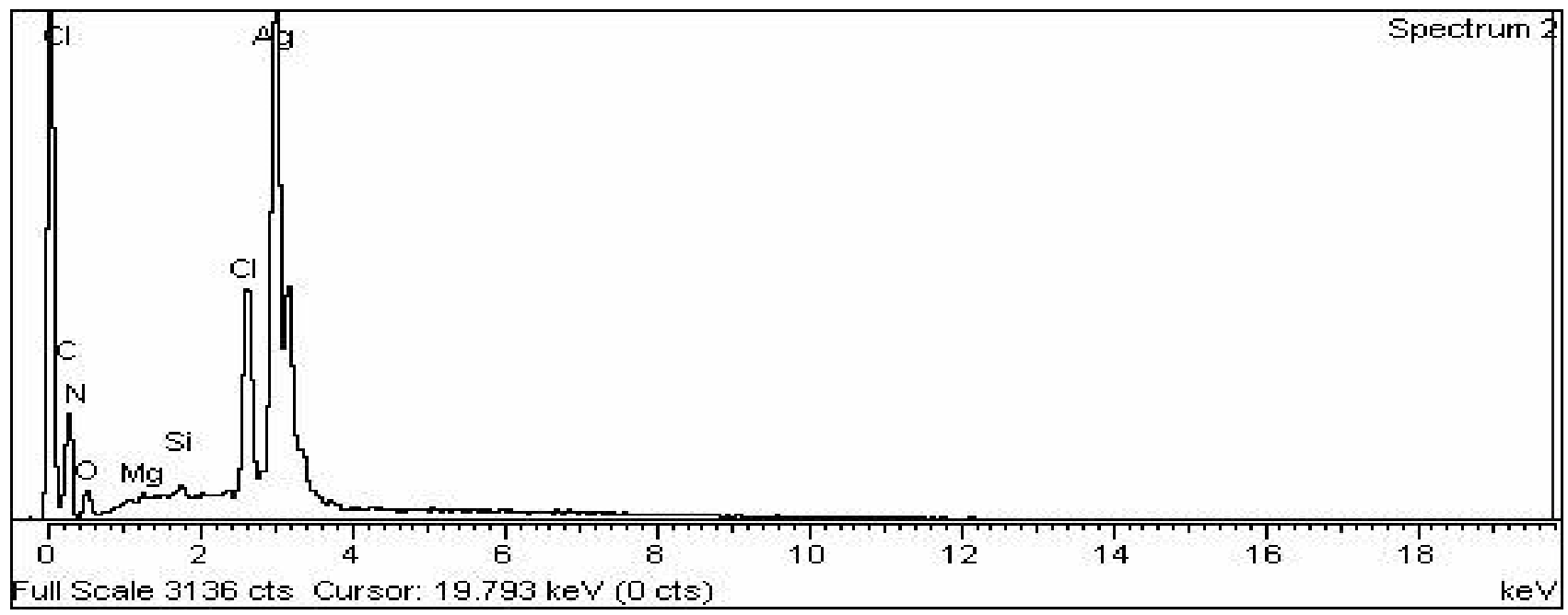

Figure 6. EDX analysis of P. niveum AgNPs.

\subsection{Acute Toxicity Test}

In a short-term toxicity assessment, the methanol extract and green generated AgNPs were shown to be non-toxic. P. niveum-treated rats did not display any outward evidence of toxicity throughout the whole trial, and no mortality was reported. Alloxan-induced diabetic rats were treated with $10 \mathrm{mg} / \mathrm{kg}$ body weight of AgNPs, which was determined to be the best dose based on acute toxicity tests. 


\subsection{Blood Glucose Level}

In order to assess the anti-hyperglycaemic impact of plant extract and phyto-synthesised AgNPs, the blood glucose levels of each group were measured over the duration of therapy (Figure 7). When compared to the diabetic control group, treatment groups (extract/AgNPs) had significantly lower blood glucose levels on days 1, 7, 14, and 21 (group DC). Compared to plant extract, AgNPs were shown to have a greater effect in lowering blood glucose levels. Groups treated with glibenclamide had substantially lower blood glucose levels compared to groups DC, DE, and DAgNPs throughout the course of therapy.

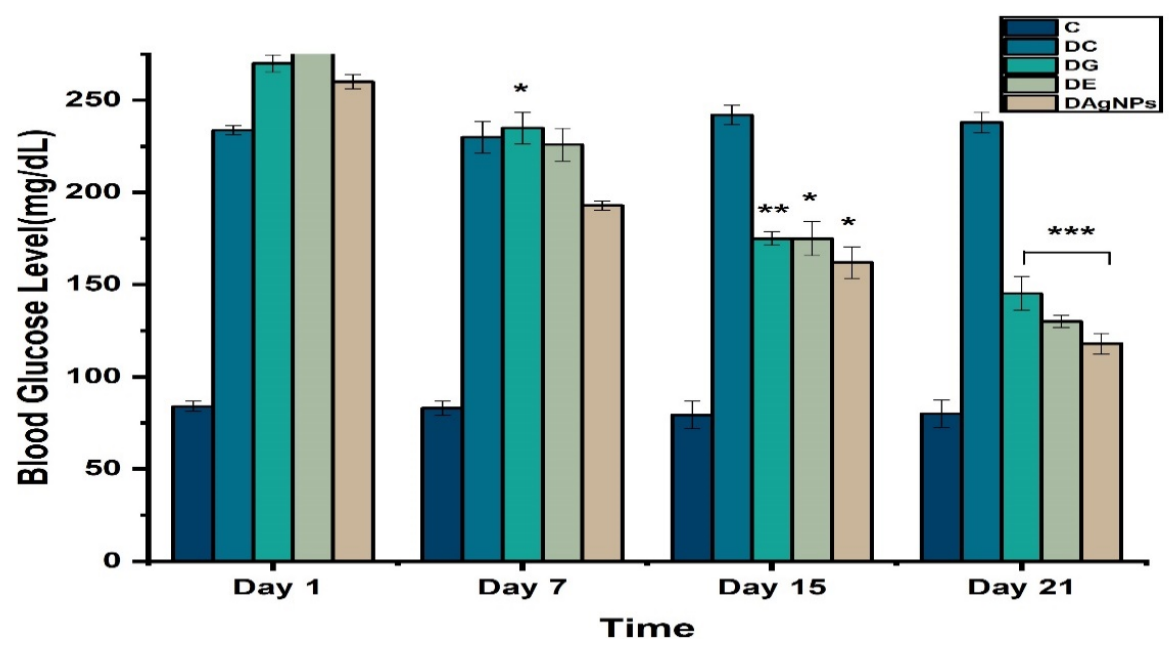

Figure 7. Effect of methanolic extract and synthesised P niveum AgNPs on blood glucose levels.

\subsection{Oral Glucose Tolerance Test}

P. niveum extract-mediated AgNP-treated diabetic rats (Figure 8) were compared to a standard treatment (glibenclamide $0.5 \mathrm{mg} / \mathrm{kg}$ ) for their ability to reduce hyperglycaemic conditions in the blood after the administration of glucose orally. Compared to group DC, animals treated with phyto-synthesised AgNPs showed a considerable improvement, with decreasing blood glucose. For groups DG, DAgNPs, and DE, their blood glucose levels decreased over a duration of two hours. According to the results, phyto-synthesised AgNP administration improves blood glucose levels equivalent to glibenclamide-treated groups, according to the results. The diabetic rat model generated by alloxan has been extensively utilised in a number of studies.

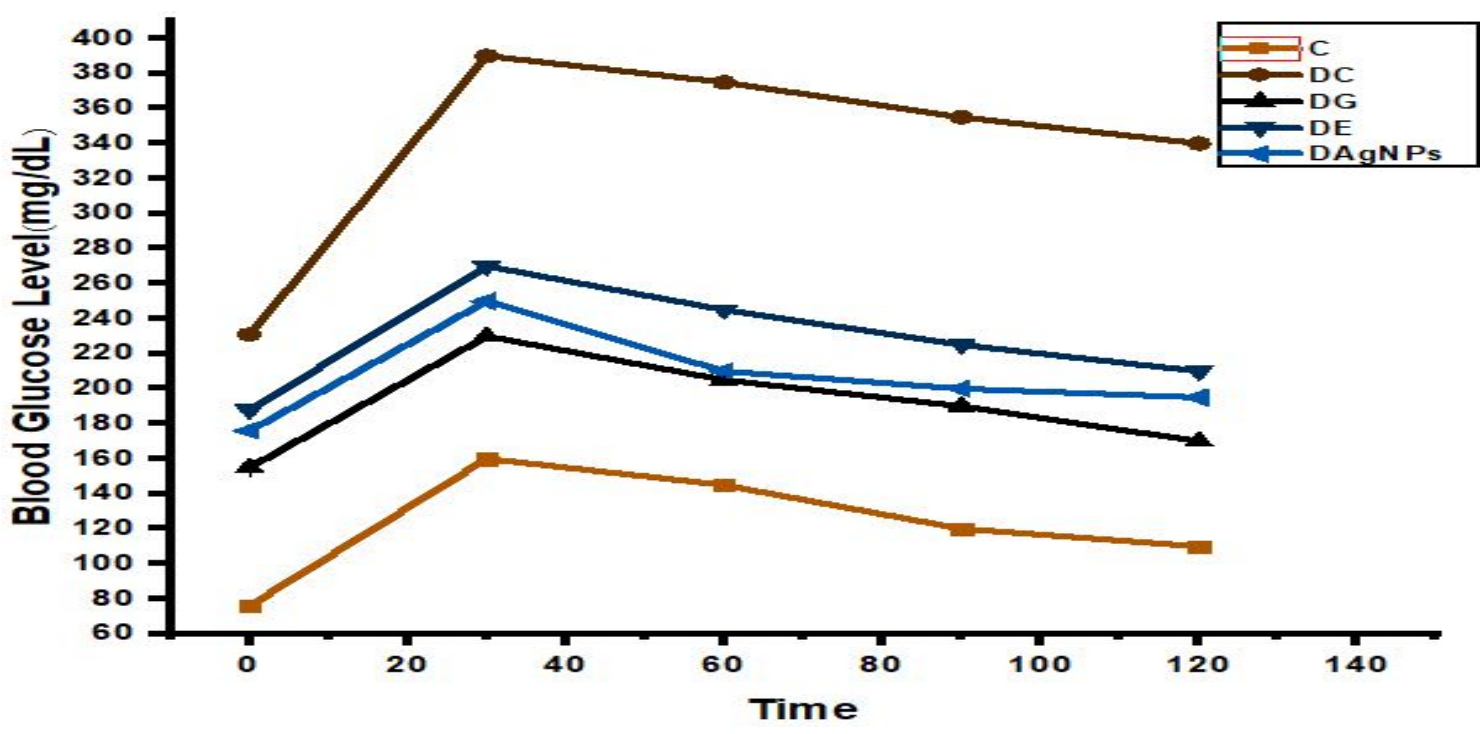

Figure 8. Effect of methanol extract and synthesised P. niveum AgNPs on oral glucose tolerance test. 


\subsection{Body Weight}

When compared to diabetic rats, oral treatment of P. niveum extract and AgNPs at a dosage of $10 \mathrm{mg} / \mathrm{kg}$ body weight daily for 21 consecutive days significantly increased body weight (Figure 9). Compared to diabetic rats in group DC, the animals in groups DE and DAgNPs gained weight on day 21. However, as compared to the normal control group, the body weight of groups DE and DAgNPs rose considerably ( $p 0.01)$. Orally, there was no difference in body weight between the glibenclamide group DG and the equivalent control group $\mathrm{C}$ after the administration of $0.5 \mathrm{mg} / \mathrm{kg}$ body weight $P$. niveum extract orally (Figure 9).

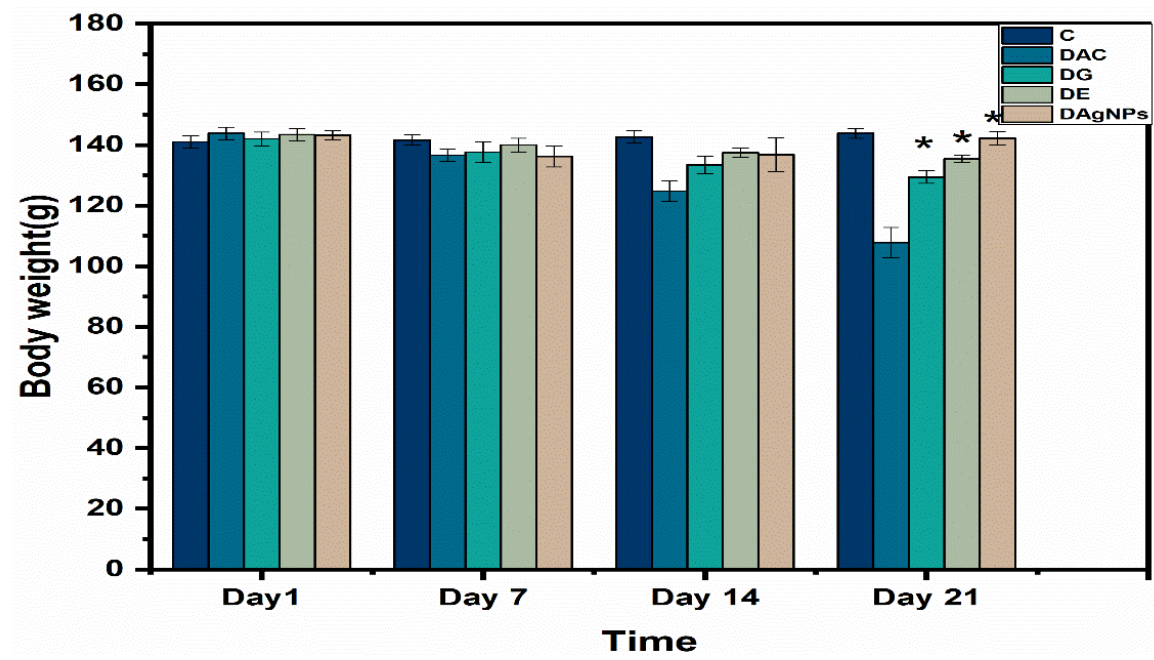

Figure 9. Effect of methanolic extract and synthesised P. niveum AgNPs on body weight.

\subsection{Serological and Urine Parameters}

The extract and green synthesised NPs showed pronounced effects on the serological parameters of various treated groups. The levels of cholesterol, HDL-c, LDL-c, and TGs in the DAC group were higher than in the DC group as a result of the weight loss (Figure 10).

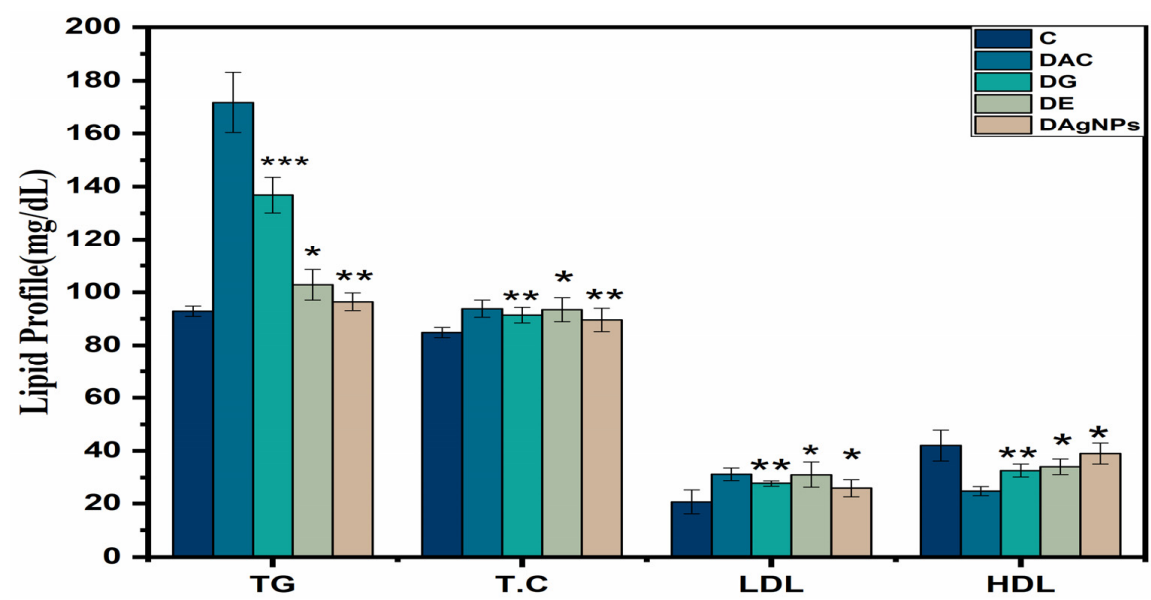

Figure 10. Effect of methanolic extract and synthesised P. niveum AgNPs on lipid profile.

The results revealed that the liver function test profile is also affected during diabetes mellitus in various treated group. The liver function was altered due to diabetes, with ALT, ALP, and SBR levels increasing in DAC compared to C (Figure 11). 


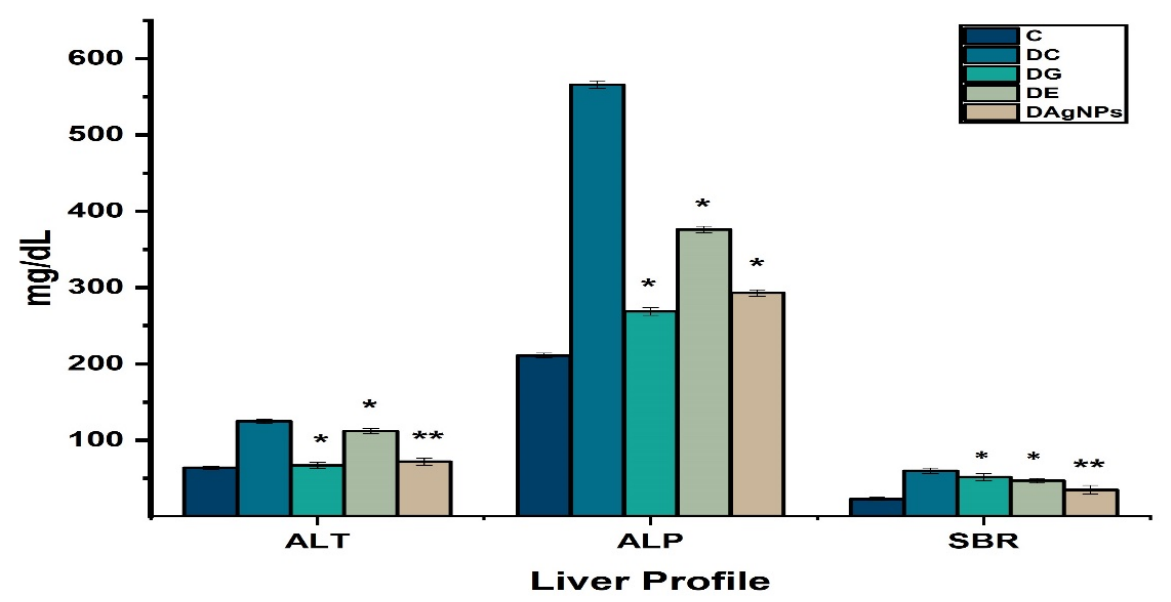

Figure 11. Effect of methanolic extract and synthesised P. niveum AgNPs on liver profile.

In addition, serological tests in the model animal (DAC) have revealed that the levels of blood urea, ALB, and creatinine are higher in the DAC group than in the C group (Figure 12).

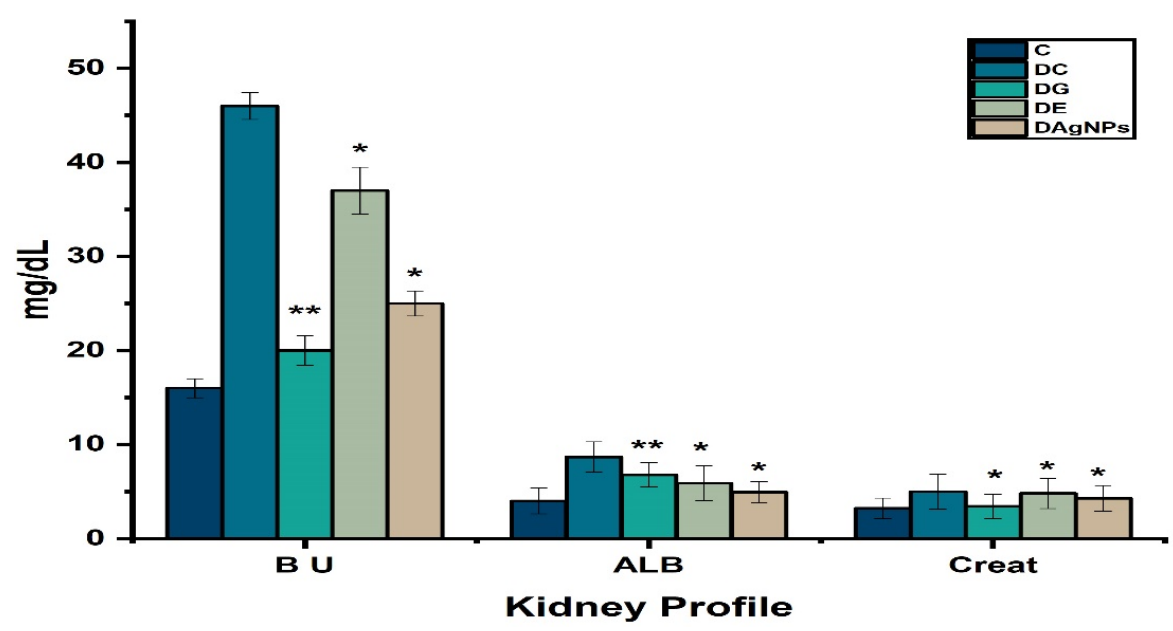

Figure 12. Effect of methanolic extract and synthesised P. niveum AgNPs on kidney profile.

The present findings revealed that the kidney function test profile is also affected during diabetes mellitus in various treated group. The majority of urine constituents are higher in DC group animals than in C group animals, according to urine analysis (Table 2).

Table 2. Effect of methanol extract and synthesised P. niveum and AgNPs on urine analysis.

\begin{tabular}{ccccccccccc}
\hline & LEU & NIT & URO & PRO & PH & BLO & SG & KET & BIL & GLU \\
\hline C & - & - & - & - & 5 & - & 1 & - & - & - \\
DC & 15 & + & 1 & $30 \pm 0.3$ & 5 & ++ & 1.01 & $15 \pm 1.5$ & 1 & $250 \pm 15$ \\
DG & 15 & + & 1 & $30 \pm 0.4$ & 6 & ++ & 1.05 & $15 \pm 1.6$ & 1 & - \\
DE & - & - & 1 & 15 & 5.5 & + & 1.01 & $15 \pm 1.7$ & 1 & - \\
DAgNPs & - & - & 1 & 15 & 5.3 & + & 1.05 & $15 \pm 1.9$ & 1 & - \\
\hline
\end{tabular}

\section{Discussion}

Phytochemical constituents in the plant samples are known to be biologically active compounds, and they are responsible for different activities, such as antioxidants, antimicrobial, antifungal, and anticancer activities [30,31]. Through different biological mechanisms, all secondary metabolite components displayed antioxidant and antimicrobial properties. Most of the secondary metabolite components were isolated and identified in the polar 
plant crude extracts [32]. The biochemical screening of the methanolic extract of $P$ niveum revealed the presence of phenols, proteins, tannins, flavonoids, alkaloids, quinones, sterols, carbohydrates, amino acids, and terpenoids.

Therefore, the detected different bioactive compounds may be responsible for the antioxidant and antibacterial activities. Several reports are available on flavonoid groups which exhibit high potential biological activities, such as antioxidant, anti-inflammatory, antimicrobial, anticancer, and anti-allergic reactions [33-36]. Tannins and their derivatives are phenolic compounds considered to be primary antioxidants or free radical scavengers [37-41].

The different parts of plant extracts are eco-friendly, economical, and safe for the synthesis of nanoparticles. In the present study, an attempt was made to synthesise silver nanoparticles from $P$. niveum whole-plant extract. For the synthesis of silver nanoparticles, standardisation was performed with respect to the addition of extract and $\mathrm{pH}$ value. The optimisation of these two parameters was essential, as both had a profound effect on the formation of silver nanoparticles. Zayed et al. [42] also reported the effect of extract amount on AgNP formation.

The colourless solution turned brown, indicating the nanoparticle formation of silver. The characteristic brown colour of silver provided a convenient spectroscopic signature to indicate nanoparticle formation. AgNPs are formed in a matter of minutes to hours, as has been reported for other plant extracts [43]. The UV spectra revealed a maximum absorption peak of $410 \mathrm{~nm}$, and the intensity of absorption increased with time. The increase in intensity could be due to the increasing number of nanoparticles formed as a result of the reduction of silver ions present in the aqueous solution with the help of phytoconstituents present in P. niveum extract. Similar results were reported by Pant et al. [44] and Roopan et al. [45].

FTIR has become an important tool in understanding the involvement of functional groups in the relations between metal particles and biomolecules. It is used to search for the chemical composition of the surface of the AgNPs and identify the biomolecules for capping and efficient stabilisation of the metal nanoparticles. There were many functional groups present that may have been responsible for the bio-reduction of Ag+ ions. The flavonoids present in the $P$. niveum extract are powerful reducing agents, which may be suggestive of the formation of silver nanoparticles through the reduction of silver nitrate. However, the probable mechanism is unclear and needs further investigation [46].

XRD analysis proved that silver nanoparticles were crystalline in nature. SEM analyses revealed that P. niveum AgNPs were spherical, hexagonal, and irregular in shape. The shape and size of nanoparticles formed vary from plant to plant and part to part, as whole plants and the phyto-constituents, such as alkaloid, flavonoids, tannins, and phenols, present in them at the time of synthesis (Table 1 ).

The AgNPs from Annona squamosa leaf extract were spherical in shape, with an average size ranging from 20 to $100 \mathrm{~nm}[47,48]$. They had spherical nanoparticles with a size ranging from 8 to $90 \mathrm{~nm}$ in Desmodium gangeticum. The sharp signal peak of silver strongly indicated the reduction of silver ions by $P$. niveum into elemental silver. Metallic silver nanoparticles generally show a typical optical absorption peak of approximately $3.25 \mathrm{keV}$ due to surface plasmon resonance. From the EDX spectrum, it was clear that $P$ niveum had a percent yield of $71.46 \%$ of AgNPs, as reported in [49].

The control group of rats (normal control group) exhibited normal blood glucose levels, whereas alloxan-induced diabetic rats (diabetic control group) showed considerably greater levels than those of the normal control rats [50]. The occurrence of hyperglycaemic conditions led to uncontrolled glucose control brought on by a change in cellular metabolism in diabetic rats [51,52]. It should be noted that diabetic rats treated with AgNPs find their biochemical parameters return to a normal level, illustrating the beneficial outcome with AgNPs. The AgNPs improved blood glucose levels, whereas P. niveum extract administration led to less hypoglycaemic activity in alloxan-induced diabetic rats. The oral administration of AgNPs and plant extract for a period of 21 days produced a significantly greater reduction in blood glucose levels than that of $P$. niveum. 
The $P$. niveum, extract, and AgNP-treated diabetic rats had a higher glucose tolerance level than the standard drug DG group, which had a lower glucose tolerance level. The DAgNP-treated animals were shown to have significantly lower blood glucose compared to DC. Among the treated groups, the efficiency rank of compounds in lowering the blood glucose level over a period of $2 \mathrm{~h}$ was the DG group, followed by the DE and DAgNPs groups. In comparison to the DC group, therapy with DAgNPs lowers blood glucose levels. The alloxan-induced diabetic rat model has been widely used in several studies $[53,54]$. In addition, the mode of action of alloxan is well documented [55]. The results obtained for blood glucose concentration in the treated groups indicated a decreased total area under the curve, which was considerably less than the DC group, and these findings are in line with previous research. In the treatment of diabetes, blood glucose concentration is regarded as a regular and key biochemical marker to evaluate the improvement in the disease status [56].

In this study, the level of change in the body weight of experimental rats before and after treatment was compared. Weight loss is one of the major syndromes associated with diabetes, probably due to muscle wasting [57]. In our study, the diabetic-induced rat group (DC) showed significant weight loss.

In $\mathrm{T} 2 \mathrm{D}$, the lipid profile is a critical element that must be maintained since elevated lipid levels increase the risk of cardiovascular infections and are usually seen in patients with poorly managed diabetes. As a result of decreased cholesterol synthesis in diabetes, the amount of cholesterol retained will rise [58]. In addition, the increased activation of fatty acids from adipose tissue leads to a disruption of lipid metabolic processes. When alloxan is administered to healthy rats, it produces hyperlipidaemia, which is evident from the increased lipid content detected in diabetic rats who were given alloxan [59]. Extracts of P. niveum and AgNPs had an influence on blood total cholesterol, triglycerides, HDL, and LDL levels. In alloxan-induced diabetic rats, cholesterol, triglycerides, and HDL levels all increased, indicating upregulation. Extended cyclic adenosine monophosphate, which is responsible for lipid production, is clearly the cause of the fluctuating blood lipid levels. Treatment with AgNPs resulted in a significant reduction in cholesterol, triglycerides, and LDL levels, as well as an increase in HDL levels in diabetic rats.

\section{Conclusions}

The AgNPs were successfully obtained from the bio-reduction of $\mathrm{AgNO}_{3}$ using P. niveum methanol extract. The NPs were appropriately characterised and confirmed using different methods, viz., UV-Vis spectroscopy, XRD, FTIR, Scanning Electron Microscopy (SEM), and EDX analysis. Acute toxicity studies were conducted and did not cause any mortality at the dose level tested (i.e., $2000 \mathrm{mg} / \mathrm{kg}$ body weight), and under our observation, the levels were considered safe. Plant-mediated NPs demonstrated antidiabetic activity significantly by lowering blood glucose levels and body weight in rats on days $1,7,14$, and 21 . The levels of blood serum cholesterol, HDL-c, LDL-c, and TGs were improved by the treatment of NPs. This is the first report demonstrating the toxicity parameters of NPs synthesised using P. niveum. Since the NPs could be useful in treating type-2 diabetes, further in vivo pharmacological investigations will clearly elucidate the mechanism of action and help in projecting the efficacy of currently synthesised NPs as a therapeutic target in treating type-2 diabetes.

Author Contributions: Conceptualization, M.N.U.H., R.A.K. and G.M.S.; methodology, A.G.; software, A.I.F.; validation, M.H.A. and H.S.Y.; formal analysis, M.H.; resources, H.M.A.; data curation, I.U.; writing—original draft preparation, M.N.U.H.; writing—review and editing, A.M.K.; visualization, S.J. and M.A.; supervision, R.A.K. and G.M.S.; project administration, R.A.K. and G.M.S.; funding acquisition, R.A.K. All authors have read and agreed to the published version of the manuscript.

Funding: We are thankful to Higher Education Commission (H.E.C) of Pakistan for financial support under the project Ref.No. 20-17575/NRPU/R\&D/HEC/2021.

Conflicts of Interest: The authors declare no conflict of interest. 


\section{Abbreviations}

\begin{tabular}{|c|c|}
\hline ALB & Albumin protein \\
\hline ALP & Alkaline phosphatase \\
\hline ALT & Alanine aminotransferase \\
\hline $\mathrm{BIL}$ & Bilirubin \\
\hline $\mathrm{BLO}$ & Blood \\
\hline BU & Blood urea \\
\hline $\mathrm{C}$ & Control \\
\hline $\mathrm{C}$ & Carbon \\
\hline $\mathrm{Ca}$ & Calcium \\
\hline $\mathrm{Cl}$ & Chlorine \\
\hline Creat & Creatinine \\
\hline $\mathrm{ddH}_{2} \mathrm{O}$ & Double-distilled water \\
\hline $\mathrm{DC}$ & Diabetic control \\
\hline $\mathrm{DE}$ & Diabetic extract \\
\hline DG & Diabetic glibenclamide \\
\hline DAgNPs & Diabetic silver nanoparticles \\
\hline DPP4 & Di peptidyl peptidase enzyme 4 \\
\hline EDX & Energy-dispersive X-ray spectroscopy \\
\hline FTIR & Fourier Transform Infrared spectroscopy \\
\hline GLU & Glucose \\
\hline HDLc & High-density lipoprotein \\
\hline KET & Ketone \\
\hline LDLc & Low-density lipoprotein \\
\hline LEU & Leukocytes \\
\hline $\mathrm{Mg}$ & Magnesium \\
\hline $\mathrm{N}$ & Nitrogen \\
\hline $\mathrm{NaOH}$ & Sodium hydroxide \\
\hline NIT & Nitrite \\
\hline $\mathrm{O}$ & Oxygen \\
\hline $\mathrm{pH}$ & Power of hydrogen ion \\
\hline $\mathrm{PRO}$ & Protein \\
\hline SBR & Serum bilirubin \\
\hline SEM & Scanning Electron Microscopy \\
\hline SGLT-2 & Sodium-glucose transport protein 2 \\
\hline SG & Specific gravity \\
\hline $\mathrm{Si}$ & Silicon \\
\hline T1D & Type-1 diabetes mellitus \\
\hline $\mathrm{T} 2 \mathrm{D}$ & Type-2 diabetes mellitus \\
\hline TGs & Tri glycerides \\
\hline URO & Urobilinogen \\
\hline UV-Vis & Ultraviolet-Visible \\
\hline XRD & X-ray diffraction \\
\hline
\end{tabular}

\section{References}

1. Santhoshkumar, J.; Rajeshkumar, S.; Kumar, S.V. Phyto-Assisted synthesis, characterization and applications of gold Nanoparticles-A review. Biochem. Biophys. Rep. 2017, 11, 46-57. [CrossRef]

2. Preethi, R.; Padma, P.R. Anticancer activity of silver nanobioconjugates synthesized from Piper betle leaves extract and its active compound eugenol. Int. J. Pharm. Pharm. Sci. 2016, 8, 201-205. [CrossRef]

3. Agarwal, H.; Kumar, S.V.; Rajeshkumar, S. A review on green synthesis of zinc oxide nanoparticles-An Eco-Friendly approach. Resour. Technol. 2017, 3, 406-413. [CrossRef]

4. Menon, S.; Rajeshkumar, S.; Kumar, V. A review on biogenic synthesis of gold nanoparticles, characterization, and its applications. Resour. Technol. 2017, 3, 516-527. [CrossRef]

5. Iravani, S. Green synthesis of metal nanoparticles using plants. Green Chem. 2011, 13, 2638-2650. [CrossRef]

6. Zhang, Z.; Cai, H.; Liu, Z.; Yao, P. Effective enhancement of hypoglycemic effect of insulin by liver-targeted nanoparticles containing cholic acid-Modified chitosan derivative. Mol. Pharm. 2016, 13, 2433-2442. [CrossRef] 
7. Arvanag, F.M.; Bayrami, A.; Habibi-Yangjeh, A.; Pouran, S.R. A comprehensive study on antidiabetic and antibacterial activities of $\mathrm{ZnO}$ nanoparticles biosynthesized using Silybum marianum L seed extract. Mater. Sci. Eng. C 2019, 97, 397-405. [CrossRef]

8. Hussein, J.; Attia, M.F.; El Bana, M.; El-Daly, S.M.; Mohamed, N.; El-Khayat, Z.; El-Naggar, M.E. Solid state synthesis of docosahexaenoic acid-loaded zinc oxide nanoparticles as a potential antidiabetic agent in rats. Int. J. Biol. Macromol. 2019, 140, 1305-1314. [CrossRef]

9. Dhas, T.S.; Kumar, V.G.; Karthick, V.; Vasanth, K.; Singaravelu, G.; Govindaraju, K. Effect of biosynthesized gold nanoparticles by Sargassum swartzii in alloxan induced diabetic rats. Enzyme Microb. Technol. 2016, 95, 100-106. [CrossRef]

10. Veiseh, O.; Tang, B.C.; Whitehead, K.A.; Anderson, D.G.; Langer, R. Managing diabetes with nanomedicine: Challenges and opportunities. Nat. Rev. Drug Discov. 2015, 14, 45-57. [CrossRef]

11. Malapermal, V.; Botha, I.; Krishna, S.B.N.; Mbatha, J.N. Enhancing antidiabetic and antimicrobial performance of Ocimum basilicum, and Ocimum sanctum (L.) using silver nanoparticles. Saudi J. Biol. Sci. 2017, 24, 1294-1305. [CrossRef] [PubMed]

12. Samadder, A.; Khuda-Bukhsh, A.R. Nanotechnological approaches in diabetes treatment: A new horizon. World J. Transl. Med. 2014, 3, 84-95. [CrossRef]

13. Thorve, V.S.; Kshirsagar, A.D.; Vyawahare, N.S.; Joshi, V.S.; Ingale, K.G.; Mohite, R.J. Diabetes-induced erectile dysfunction: Epidemiology, pathophysiology and management. J. Diabetes Complicat. 2011, 25, 129-136. [CrossRef] [PubMed]

14. Wright, E., Jr.; Scism-Bacon, J.L.; Glass, L.C. Oxidative stress in type 2 diabetes: The role of fasting and postprandial glycaemia. Int. J. Clin. Pract. 2006, 60, 308-314. [CrossRef]

15. Anderson, M.; Powell, J.; Campbell, K.M.; Taylor, J.R. Optimal management of type 2 diabetes in patients with increased risk of hypoglycemia. Diabetes Metab. Syndr. Obes. Targets Ther. 2014, 7, 85.

16. Volpe, C.M.O.; Villar-Delfino, P.H.; dos Anjos, P.M.F.; Nogueira-Machado, J.A. Cellular death, reactive oxygen species (ROS) and diabetic complications. Cell Death Dis. 2018, 9, 119. [CrossRef]

17. Ali, S.I.; Qaiser, M.; Abid, R. Flora Pakistan; No. 210: Asteraceae (II) inuleae, Plucheeae, Gnaphalieae; MBG Press: St. Louis, MO, USA, 2003; Volume 210.

18. Nisar-Ul-Haq, M.; Wazir, S.M.; Ullah, F.; Khan, R.A.; Shah, M.S.; Khatak, A. Phytochemical and biological evaluation of defatted seeds of Jatropha curcas. Sains Malays. 2016, 45, 1435-1442.

19. Jayapriya, G.; Shoba, F.G. Screening for phytochemical activity of Urechites lutea plant. Asian J. Plant Sci. Res. 2014, 4, 20-24.

20. Savithramma, N.; Rao, M.L.; Suhrulatha, D. Screening of medicinal plants for secondary metabolites. Middle-East J. Sci. Res. 2011, $8,579-584$

21. Khan, N.A.; Niaz, A.; Zaman, M.I.; Khan, F.A.; Nisar-Ul-Haq, M.; Tariq, M. Sensitive and selective colorimetric detection of Pb ${ }^{2+}$ by silver nanoparticles synthesized from Aconitum violaceum plant leaf extract. Mater. Res. Bull. 2018, 102, 330-336. [CrossRef]

22. Prakash, P.; Gnanaprakasam, P.; Emmanuel, R.; Arokiyaraj, S.; Saravanan, M. Green synthesis of silver nanoparticles from leaf extract of Mimusops elengi, Linn. for enhanced antibacterial activity against multi drug resistant clinical isolates. Colloids Surf. B Biointerfaces 2013, 108, 255-259. [CrossRef]

23. Das, G.; Patra, J.K.; Debnath, T.; Ansari, A.; Shin, H.-S. Investigation of antioxidant, antibacterial, antidiabetic, and cytotoxicity potential of silver nanoparticles synthesized using the outer peel extract of Ananas comosus (L.). PLoS ONE 2019, 14, e0220950. [CrossRef]

24. Sengottaiyan, A.; Aravinthan, A.; Sudhakar, C.; Selvam, K.; Srinivasan, P.; Govarthanan, M.; Manoharan, K.; Selvankumar, T. Synthesis and characterization of Solanum nigrum-Mediated silver nanoparticles and its protective effect on alloxan-Induced diabetic rats. J. Nanostruct. Chem. 2016, 6, 41-48. [CrossRef]

25. Xu, Z.P.; Zeng, Q.H.; Lu, G.Q.; Yu, A.B. Inorganic nanoparticles as carriers for efficient cellular delivery. Chem. Eng. Sci. 2006, 61, 1027-1040. [CrossRef]

26. Raut, N.A.; Gaikwad, N.J. Antidiabetic activity of hydro-Ethanolic extract of Cyperus rotundus in alloxan induced diabetes in rats. Fitoterapia 2006, 77, 585-588. [CrossRef]

27. Vessal, M.; Hemmati, M.; Vasei, M. Antidiabetic effects of quercetin in streptozocin-induced diabetic rats. Comp. Biochem. Physiol. Part C Toxicol. Pharmacol. 2003, 135, 357-364. [CrossRef]

28. Mansour, H.A.; Newairy, A.-S.A.; Yousef, M.I.; Sheweita, S.A. Biochemical study on the effects of some Egyptian herbs in alloxan-Induced diabetic rats. Toxicology 2002, 170, 221-228. [CrossRef]

29. Hossain, M.A.; Nagooru, M.R. Biochemical profiling and total flavonoids contents of leaves crude extract of endemic medicinal plant Corydyline terminalis L. Kunth. Pharmacogn. J. 2011, 3, 25-30. [CrossRef]

30. Akharaiyi, F.C. Antibacterial, phytochemical and antioxidant activities of Datura metel. Int. J. PharmTech Res. $2011,3,478-483$.

31. Suresh, S.N.; Nagarajan, N. Antimicrobial activity and preliminary phytochemical analysis of Begonia malabarica Lam. J. Pure Appl. Microbiol. 2009, 3, 801-803.

32. Gonzalez-Guevara, J.L.; Gonzalez-Lavaut, J.A.; Pino-Rodriguez, S.; Garcia-Torres, M.; Carballo-Gonzalez, M.T.; EchemendiaArana, O.A.; Molina-Torres, J.; Prieto-Gonzalez, S. Phytochemical screening and in vitro antiherpetic activity of four Erythtroxylum species. Acta Farm. Bonaer 2004, 23, 506-509.

33. Anyasor, G.N.; Ogunwenmo, O.; Oyelana, O.A.; Akpofunure, B.E. Phytochemical constituents and antioxidant activities of aqueous and methanol stem extracts of Costus afer Ker Gawl. (Costaceae). Afr. J. Biotechnol. 2010, 9, 4880-4884.

34. Lee, C.P.-D.; Hsiu, S.-L.; Hou, Y.-C. Flavonoids in herbs: Biological fates and potential interactions with xenobiotics. J. Food Drug Anal. 2002, 10, 3. [CrossRef] 
35. Igbinosa, O.O.; Igbinosa, E.O.; Aiyegoro, O.A. Antimicrobial activity and phytochemical screening of stem bark extracts from Jatropha curcas (Linn). Afr. J. Pharm. Pharmacol. 2009, 3, 58-62.

36. Thitilertdecha, N.; Teerawutgulrag, A.; Rakariyatham, N. Antioxidant and antibacterial activities of Nephelium lappaceum L. extracts. LWT-Food Sci. Technol. 2008, 41, 2029-2035. [CrossRef]

37. Barile, E.; Bonanomi, G.; Antignani, V.; Zolfaghari, B.; Sajjadi, S.E.; Scala, F.; Lanzotti, V. Saponins from Allium minutiflorum with antifungal activity. Phytochemistry 2007, 68, 596-603. [CrossRef]

38. Ayoola, G.A.; Coker, H.A.; Adesegun, S.A.; Adepoju-Bello, A.A.; Obaweya, K.; Ezennia, E.C.; Atangbayila, T.O. Phytochemical screening and antioxidant activities of some selected medicinal plants used for malaria therapy in Southwestern Nigeria. Trop. J. Pharm. Res. 2008, 7, 1019-1024.

39. Vadlapudi, V.; Kaladhar, D. Antimicrobial study of plant extracts of Datura metel L. against some important disease causing pathogens. Asian Pac. J. Trop. Dis. 2012, 2, S94-S97. [CrossRef]

40. Sekar, D.; Kolanjinathan, K.; Saranraj, P.; Gajendiran, K. Screening of Phyllanthus amarus, Acalypha indica and Datura metel for its antimicrobial activity against selected pathogens. Int. J. Pharm. Biol. Arch. 2012, 3, 1231-1236.

41. Zayed, M.F.; Eisa, W.H.; Shabaka, A.A. Malva parviflora extract assisted green synthesis of silver nanoparticles. Spectrochim. Acta Part A Mol. Biomol. Spectrosc. 2012, 98, 423-428. [CrossRef]

42. Chanda, S. Silver nanoparticles (medicinal plants mediated): A new generation of antimicrobials to combat microbial pathogens-A review. In Microbial Pathogens and Strategies for Combating Them: Science, Technology and Education; Formatex Research Center: Badajoz, Spain, 2013; pp. 1314-1323.

43. Pant, G.; Nayak, N.; Prasuna, R.G. Enhancement of antidandruff activity of shampoo by biosynthesized silver nanoparticles from Solanum trilobatum plant leaf. Appl. Nanosci. 2013, 3, 431-439. [CrossRef]

44. Roopan, S.M.; Madhumitha, G.; Rahuman, A.A.; Kamaraj, C.; Bharathi, A.; Surendra, T.V. Low-Cost and Eco-Friendly Phyto-Synthesis of silver nanoparticles using Cocos nucifera coir extract and its larvicidal activity. Ind. Crops Prod. 2013, 43, 631-635. [CrossRef]

45. Vivek, R.; Thangam, R.; Muthuchelian, K.; Gunasekaran, P.; Kaveri, K.; Kannan, S. Green biosynthesis of silver nanoparticles from Annona squamosa leaf extract and its in vitro cytotoxic effect on MCF-7 cells. Process Biochem. 2012, 47, 2405-2410. [CrossRef]

46. El-Bindary, A.; Anwar, Z.; El-Shafaie, T. Effect of silicon dioxide nanoparticles on the assessment of quercetin flavonoid using Rhodamine B Isothiocyanate dye. J. Mol. Liq. 2021, 323, 114607. [CrossRef]

47. El-Gammal, O.A.; Mohamed, F.S.; Rezk, G.N.; El-Bindary, A.A. Synthesis, characterization, catalytic, DNA binding and antibacterial activities of $\mathrm{Co}$ (II), Ni (II) and Cu (II) complexes with new Schiff base ligand. J. Mol. Liq. 2021, 326, 115223. [CrossRef]

48. El-Bindary, M.A.; El-Bindary, A.A. Synthesis, characterization, DNA binding, and biological action of dimedone arylhydrazone chelates. Appl. Organomet. Chem. 2022, e6576. [CrossRef]

49. Thirunavoukkarasu, M.; Balaji, U.; Behera, S.; Panda, P.K.; Mishra, B.K. Biosynthesis of silver nanoparticle from leaf extract of Desmodium gangeticum (L.) DC. and its biomedical potential. Spectrochim. Acta Part A Mol. Biomol. Spectrosc. 2013, 116, 424-427. [CrossRef]

50. Zaheer, Z.; Rafiuddin, H.S. Bio-Conjugated silver nanoparticles: From Ocimum sanctum and role of cetyltrimethyl ammonium bromide. Colloids Surf. B Biointerfaces 2013, 108, 90-94. [CrossRef]

51. Charbgoo, F.; Ahmad, M.B.; Darroudi, M. Cerium oxide nanoparticles: Green synthesis and biological applications. Int. J. Nanomed. 2017, 12, 1401. [CrossRef]

52. Gylling, H.; Miettinen, T.A. Cholesterol absorption, synthesis, and LDL metabolism in NIDDM. Diabetes Care 1997, 20, 90-95. [CrossRef]

53. Ragini, V.; KVSRG, P.; Bharathi, K. Antidiabetic and antioxidant activity of Shorea tumbuggaia Rox. Int. J. Innov. Pharm. Res. 2011, 2, 113-121.

54. Attanayake, A.P.; Jayatilaka, K.A.P.W.; Pathirana, C.; Mudduwa, L.K.B. Study of antihyperglycaemic activity of medicinal plant extracts in alloxan induced diabetic rats. Anc. Sci. Life 2013, 32, 193. [CrossRef] [PubMed]

55. Fröde, T.S.; Medeiros, Y.S. Animal models to test drugs with potential antidiabetic activity. J. Ethnopharmacol. 2008, 115, 173-183. [CrossRef] [PubMed]

56. Swanston-Flatt, S.K.; Day, C.; Bailey, C.J.; Flatt, P.R. Traditional plant treatments for diabetes. Studies in normal and streptozotocin diabetic mice. Diabetologia 1990, 33, 462-464. [CrossRef] [PubMed]

57. Eleazu, C.O.; Eleazu, K.C.; Ironkwe, A.; Iroaganachi, M.A. Effect of Livingstone potato (Plectranthus esculenthus NE Br) on diabetes and its complications in streptozotocin induced diabetes in rats. Diabetes Metab. J. 2014, 38, 366-374. [CrossRef] [PubMed]

58. Shaik, A.H.; Rasool, S.N.; Reddy, A.V.K.; Kareem, M.A.; Krushna, G.S.; Devi, K.L. Cardioprotective effect of HPLC standardized ethanolic extract of Terminalia pallida fruits against isoproterenol-induced myocardial infarction in albino rats. J. Ethnopharmacol. 2012, 141, 33-40. [CrossRef]

59. Shanmugasundaram, E.R.B.; Rajeswari, G.; Baskaran, K.; Kumar, B.R.R.; Shanmugasundaram, K.R.; Ahmath, B.K. Use of Gymnema sylvestre leaf extract in the control of blood glucose in insulin-dependent diabetes mellitus. J. Ethnopharmacol. 1990, 30, 281-294. [CrossRef] 